\title{
Quercetin Influence on Thermal Denaturation of Bovine Serum Albumin
}

Aurica Precupas, Romica Sandu, Vlad T. Popa*

"Ilie Murgulescu" Institute of Physical Chemistry of the Romanian Academy, Splaiul

Independentei 202, Bucharest, 060021, Romania. 


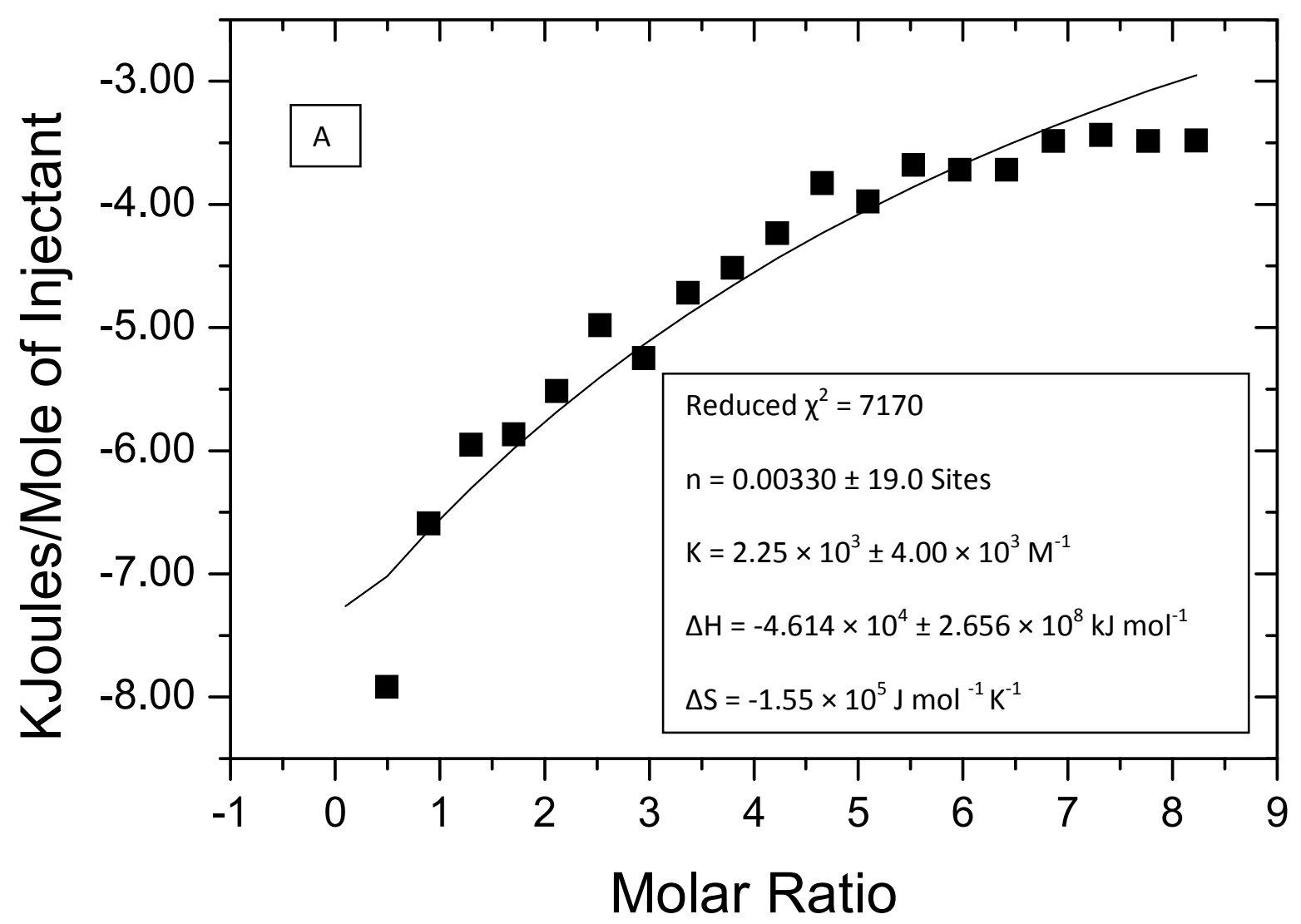




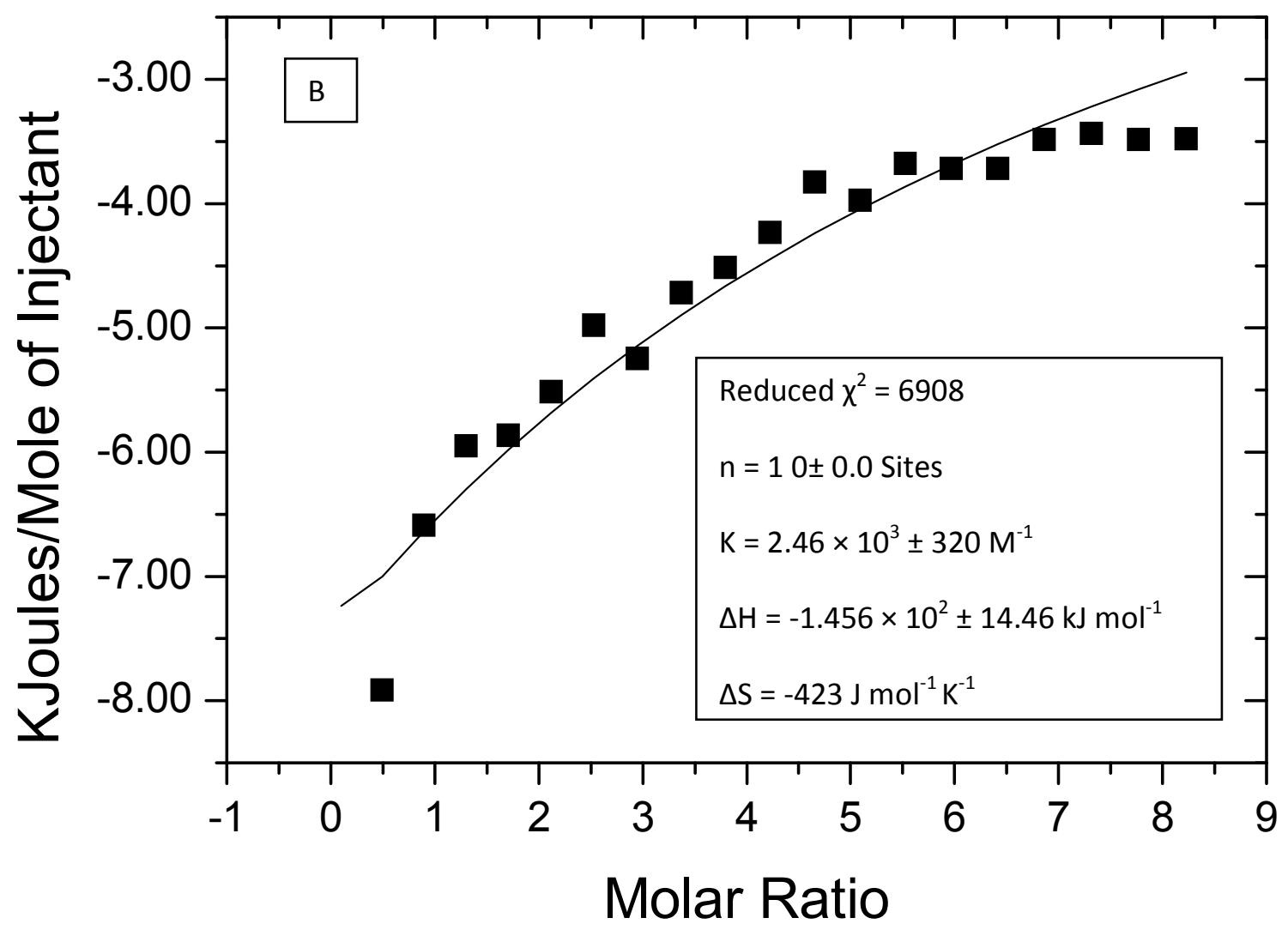

Figure S1. ITC data fit of a single set of independent binding sites model (A) or considering $n=1$ fixed (B) for the titration of $2.1 \times 10^{-5} \mathrm{M}$ BSA with $9.71 \times 10^{-4} \mathrm{M}$ quercetin at $\mathrm{pH} 7.4$ and $298 \mathrm{~K}$. 


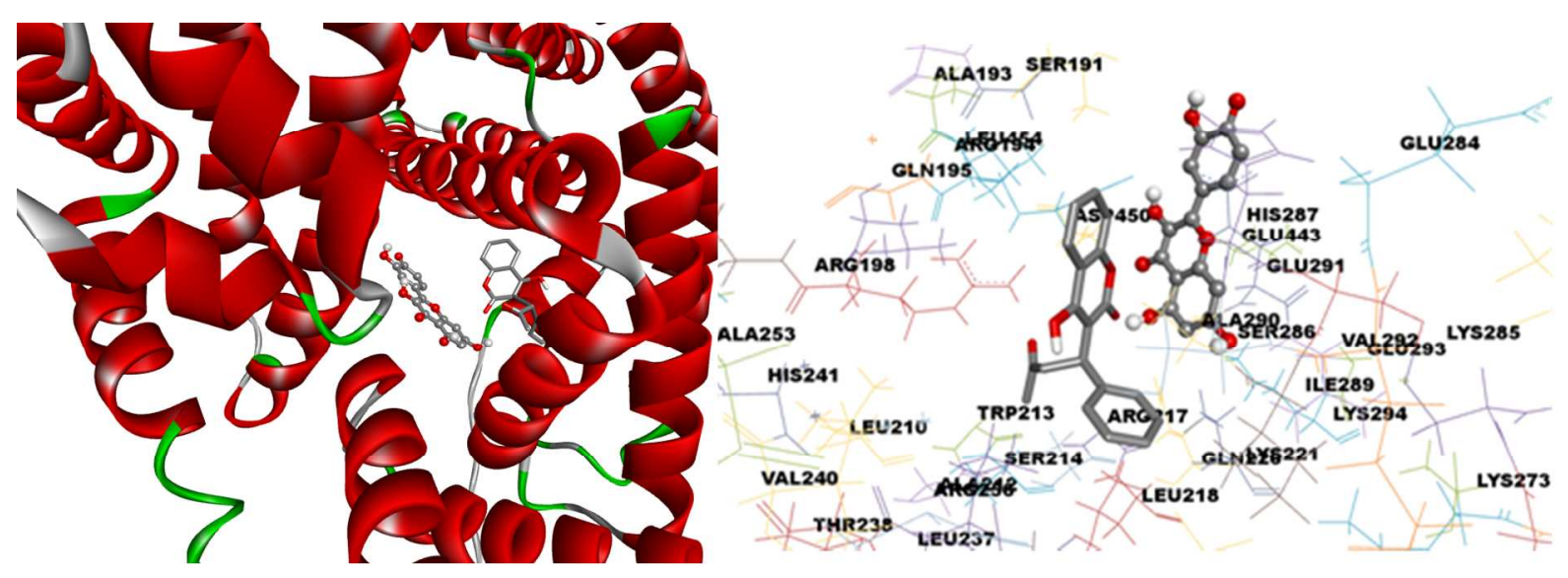

Figure S2. The mutual positions of quercetin and warfarin in the cavity of subdomain IIA, calculated by molecular docking. Quercetin is shown as ball and stick model, warfarin as stick model. Warfarin and quercetin structures were optimized by the DFT method. ${ }^{1}$

1. Gaussian 03, Revision C.01, Frisch, M. J.; Trucks, G. W.; Schlegel, H. B.; Scuseria, G. E.; Robb, M. A.; Cheeseman, J. R.; Montgomery, Jr., J. A.; Vreven, T.; Kudin, K. N.; Burant, J. C.; Millam, J. M.; Iyengar, S. S.; Tomasi, J.; Barone, V.; Mennucci, B.; Cossi, M.; Scalmani, G.; Rega, N.; Petersson, G. A.; Nakatsuji, H.; Hada, M.; Ehara, M.; Toyota, K.; Fukuda, R.; Hasegawa, J.; Ishida, M.; Nakajima, T.; Honda, Y.; Kitao, O.; Nakai, H.; Klene, M.; Li, X.; Knox, J. E.; Hratchian, H. P.; Cross, J. B.; Bakken, V.; Adamo, C.; Jaramillo, J.; Gomperts, R.; Stratmann, R. E.; Yazyev, O.; Austin, A. J.; Cammi, R.; Pomelli, C.; Ochterski, J. W.; Ayala, P. Y.; Morokuma, K.; Voth, G. A.; Salvador, P.; Dannenberg, J. J.; Zakrzewski, V. G.; Dapprich, S.; Daniels, A. D.; Strain, M. C.; Farkas, O.; Malick, D. K.; Rabuck, A. D.; Raghavachari, K.; Foresman, J. B.; Ortiz, J. V.; Cui, Q.; Baboul, A. G.; Clifford, S.; Cioslowski, J.; Stefanov, B. B.; Liu, G.; Liashenko, A.; Piskorz, P.; Komaromi, I.; Martin, R. L.; Fox, D. J.; Keith, T.; Al- 
Laham, M. A.; Peng, C. Y.; Nanayakkara, A.; Challacombe, M.; Gill, P. M. W.; Johnson, B.; Chen, W.; Wong, M. W.; Gonzalez, C.; and Pople, J. A.; Gaussian, Inc., Wallingford CT, 2004. 